of June 20th, 1896, this resource is distinctly objectionable. By Van Houten's process (the original Datch method) a real improvement in the manufacture of cocoa which considerably added to the dietetic value of the product was effected. In this process the cocoa is not at any time or in any way prepared or treated with carbonate of potash, ammonia, or other alkali. The impression that it was so treated arose from the fact that on burning the cocoa so prepared a strongly alkaline and an increased ash was obtained. As a matter of fact, the decoction of Messrs. Van Houten's cocoa shows a faintly, though distinctly, acid reaction. It is just as logical to conclude that claret contains free alkali. Claret is of course strongly acid, but on burning the acid residue of the wine a strongly alkaline ash consisting of potassium carbonate remains. The important improvement in the dietetic properties of Messrs. Van Houten's cocoa consists in the enrichment of the cocoa by the addition of a trifling quantity of certain neutral salts, which, it is important to add, are perfectly normal constituents of the cocoa itself. War from being objectionable, this procedure is fully justified by the evidence of experience as to the increased dietetic value of the cocoa so prepared. In a recent analysis which we have made the results distinctly indicate the advantage of this method. Thus this cocoa yields a decoction containing a maximum proportion of the valuable food constituents of the bean; and, of more importance still, these are presented in a condition more easy of assimilation and digestion than in cocoa not so prepared. The addition of a free alkali is, we hold, objectionable, because we have season for believing that it would act unfavourably on the mourishing and stimulating cocoa substances. When cocoa, for example, is treated with alkali, an ammoniacal smell is at once evolved, which is probably due to the decomposition of the nitrogenous stimulating substances, as theo-brounine. In Messrs. Van Houten's cocoa, on the contrary, there is absolutely no free alkali, while the method of preparation undoubtedly adds to its nourishing properties and, more important still, to its digestibility. It has been said that one of the objects of adding alkali to cocoa is to partly saponify the fat and thus give the decoction a rich and frothy appearance. There is absolutely no trace of soap, we ind, in Van Houten's cocoa. The important effect of Van Houten's process is, however, to increase the miscibility of the cocoa with water or milk, and to enrich it by the addition of a small proportion of its own natural constituents. An important economy is thus ensured. This treatment further tends to develop that fine aroma and flavour which make cocoa an acceptable beverage.

\section{"APPLE JUIOE."}

(The Apple Juice Co., 143, Canvon STREet, E.C.)

This is a fermented beverage like cider with a small alcoholic strength. Analysis gave the following results : Alcohol, by weight 5.25 per cent., by volume 655 per cent., equal to proof spirit 11.49 per cent.; acetic acid, 0.39 per cent.; malic acid, 0.43 per cent. ; total extractives, 855 per cent.; mineral matter, 0.31 per cent. The excessive amount of volatile acid or acetic acid is an objectionable feature in this analysis. This result is borne out by the unpleasant sour taste, which is quite different from that of the fixed acids of the apple. Acetification has evidently set in, in spite of the juice being preserved, as we found, with salicylic acid. This fact, coupled with the quantity of saccharine matters present, renders this preparation not as wholesome as it might be.

EASTON'S SYRUP PALATINOIDS.

(OPPENHEIMER, SON, AND CO., 17, WORSHIP-STREET, E.C.)

Palatinoids containing the equivalent of half a drachm of Easton syrup have recently been prepared. The contents consist of a bluish-grey, finely divided powder, containing phosphate of iron in an unoxidised condition, together with quinine and strychnine. The advantages of Kaston's syrup in this form (that is, in a jujube, excluding the deteriorating influences of the air) are obvious. The formula is excellent and the constituents are preserved in their original state.

"CYMRALIS" TABLE WATER.

(R. Ellis and Son, RUTHLi, N. Wales.)

This effervescing water is bright, well aerated, and commendably soft to the taste. The water-supplies of North Wales are admirably adapted for the preparation of aerated waters since they are so pure. Cymralis, we find, is slightly and agreeably mineralised. The total solid matter amounted to 0.88 gramme per litre. It is slightly alkaline, the degree of alkalinity being equivalent to 0.25 gramme of bi-carbonate of soda per litre. This, coupled with the purity of the gas employed, accounts for the peculiarly soft flavour of the water.

SANITAS DISINFECTANT SOAP.

(The Sanitas Co., Bexhmal Green, E.)

Sanitas has the distinct merit that though a decided disinfectant it has an agreeable smell. Further, it is quite compatible with soap. A specimen of sanitas soap recently submitted to us had somewhat the appearance and character of soft soap, but it proved to be a neutral soda soap, free from irritants. It evidently contains a good proportion of sanitas oil. For cleansing and detergent purposes it should answer admirably.

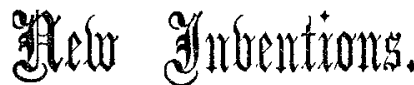

\section{AN EFHICIENT DRAINAGE PLUG.}

For some two years past in cases where it has been necessary for me to make a permanent opening into any of the viscera, my attention has been specially directed towards devising some plan to relieve patients from the extreme discomfort which arises from lack of proper plug or conduit, and after repeated experiments I have now decided upon a very simple plan, which has proved so eminently satisfactory that I am sure it will meet the well-known difficulties of such cases. As shown in the diagram it consists of a tube with a flange and a pear-shaped expansion at the end, which is inserted into the viscus. This with a plug or clip answers well for gastrostomies. For the gall-bladder, \&c., it is only necessary to attach a receiver. My experience with this plug has been so satisfactory in the already mentioned operations that recently I have tried it in a case of left inguinal colotomy, simply dispensing with the tubing portion and keeping it in position by a hollow padded colotomy truss; it is answering most satis.

factorily. Simple as the contrivance is, it has only been arrived at after numerous experiments as to shape, \&c., and correctness in these details is essential. I now find I can effectually plug without distending the opening, so that it is not necessary to be constantly changing the size; and, again, the action is in some respects automatic, as a sudden impulse, such as coughing and the like, tends to expand the pearshaped extremity so that it neither allows of its own expnlsion nor the escape of fluid by its side. The particulars I have mentioned govern the construction of the plugs when empluyed for any purpose, but it is essential to have them made of a suitable size and with suitably shaped necks to meet the requirements of each case. Such details can be had from Messrs. Down Brothers, 21, St. Thomas's.street, London, S.E., who have afforded me invaluable assistance in carrying out the experiments.

Cavendish-square, $\mathrm{W}$. 